\title{
Participación \\ ciudadana y planeación del ordenamiento territorial en la frontera norte de México
}

Introducción

En medio de la despolitización, la individualización ciudadana y la presión que los grupos de interés económico ejercen sobre el territorio, aparecen esfuerzos que buscan conciliar intereses, decantar problemas y encontrar alternativas de solución vía la participación ciudadana.

La participación ciudadana es un requisito de las democracias modernas en la construcción de la política pública. En la planeación del ordenamiento territorial, esta se realiza mediante herramientas de consulta como los talleres de planeación participativa (TPP). En este estudio se analiza la participación ciudadana en tres casos de planeación del territorio en el norte de México. Se demuestra que los TPP son un buen instrumento para la deliberación, pero se requiere fortalecer el marco institucional para abrir mayores espacios de participación efectiva de la sociedad.

Palabras clave: gobernanza, ordenamiento del territorio, participación ciudadana, planeación, talleres de planeación participativa.

-Investigadora (estancia posdoctoral) en El Colegio de la Frontera Norte.

bvmtzfs@gmail.com

- Profesora-Investigadora del Departamento de Estudios Urbanos y del Medio Ambiente de El Colegio de la Frontera Norte.

Iromo@colef.mx

•*Profesor-Investigador del Departamento de Estudios Urbanos y del Medio Ambiente de El Colegio de la Frontera Norte.

gcordova@colef.mx
Esta involucra a distintos sectores de la población que, en función de sus propios intereses, intervienen directamente o por medio de sus representantes y organizaciones en los distintos aspectos de la vida colectiva (Arteaga, 2003, pp. 69-78).

La participación ciudadana puede ser medida en función de la capacidad que tienen los actores sociales para interactuar y verter sus opiniones en mesas de diálogo de cara a otros actores con intereses particulares. Para Graizbord (1999, pp. 149-161), la participación ciudadana, en el ámbito de la política, debe permitir evaluar la capacidad de los ciudadanos como individuos, o bien, como grupos organizados, para obtener respuesta a sus demandas o influir en las decisiones y acciones que lleva a cabo el Gobierno. 
En este trabajo se da cuenta de la capacidad de la participación ciudadana para la elaboración de programas de ordenamiento urbano, ecológico y territorial, extendidos gracias al afán del Estado por regular la expansión urbana, paliar los efectos de esta y asegurar la distribución del suelo, anteponiendo los principios de sustentabilidad ambiental. En efecto, agentes e instituciones convocan a la ciudadanía, grupos económicos, académicos y funcionarios públicos para que, con base en su experiencia de vida, interés particular o desempeño institucional, identifiquen problemáticas, ofrezcan alternativas de solución a partir del consenso y den cauce legal e institucional para planear y ordenar el territorio.

Así, se analiza la incidencia de la participación ciudadana en la planeación del territorio en tres demarcaciones de la frontera norte de México: los municipios de Nogales, en el estado de Sonora, y Juárez, en Chihuahua, así como el estado de Coahuila. En cada uno de estos espacios previamente se elaboraron instrumentos de política territorial: el Programa de Ordenamiento Ecológico Local del Municipio de Nogales, Sonora (Romo, 2009); el Programa de Ordenamiento Ecológico Territorial del Municipio de Juárez (Romo, 2010); y el Programa de Desarrollo Urbano y Ordenamiento Territorial del Estado de Coahuila (Romo, 2012).

En estos, se aplicó la metodología de planeación territorial participativa (PTP), que Sánchez (2007) entiende como "un proceso a partir del cual se despliega una práctica sociopolítica [...] en que diferentes actores con intereses legítimos se pueden involucrar en la valoración de propuestas de desarrollo y en la toma de decisiones" (p. 32). Con el PTP se busca hacer frente al enfoque centralista y racional para fomentar el arraigo local, la viabilidad y la vigilancia del territorio (Salamanca, et al., 2001, p. 5).

Siguiendo este enfoque, se ha planteado como objetivo de este trabajo analizar la participación ciudadana y su 
incidencia en la planeación del ordenamiento urbano, ecológico y territorial en el norte de México mediante el uso de los talleres de planeación participativa (TPP), en los que los actores provenientes de la sociedad civil -productores, miembros de organizaciones civiles y académicos-, así como actores gubernamentales, participan en un mismo plano en tres diferentes escenarios. Se describen así el proceso de identificación de problemas, las alternativas de solución propuestas por los actores y los factores institucionales que posibilitan la implementación de esas propuestas en los diferentes órdenes de Gobierno.

En los casos estudiados, se observó la participación de aquellos actores que se consideran clave por sus conocimientos, por sus actividades sectoriales y por sus experiencias relativas al uso de suelo, la explotación de los recursos naturales y las externalidades que provoca el mal manejo del territorio, lo anterior bajo la coordinación de un equipo técnico (ET) que proporcionó los diagnósticos iniciales de la realidad física, ambiental, económica y territorial de esos lugares.

Para cumplir con el objetivo, se ha dividido el trabajo en cinco apartados. Primeramente, se brinda un panorama teórico de la planeación participativa y la sustentabilidad ambiental; enseguida, se describe el procedimiento metodológico utilizado en los TPP; se prosigue con una descripción geográfica y socioeconómica de los tres escenarios; posteriormente, se da cuenta de la participación ciudadana por medio de los problemas y alternativas que identifican los actores, así como de aquellos factores institucionales que inciden en la planeación de la ordenación urbana, ecológica y territorial. Finalmente, se presentan las consideraciones del análisis a manera de conclusión. 


\section{Planeación participativa y sustentabilidad ambiental}

La planeación del territorio se remonta a las estrategias de desarrollo enmarcadas en periodos de crisis económicas, tanto en países industrializados como en países emergentes. En los países latinoamericanos, el ordenamiento del territorio se da como respuesta a los fuertes desequilibrios territoriales provocados por el modelo de sustitución de importaciones, caracterizado por un proceso de industrialización y explotación intensiva de recursos naturales, y un acelerado crecimiento demográfico que indujo a una ocupación territorial desordenada y a una concentración de población y de actividades productivas en un número reducido de ciudades (Massiris, 2006, p. 24).

De acuerdo con De Mattos (1986, p. 14), una de las primeras experiencias de planeación regional en América Latina fue la concepción del desarrollo integrado por cuencas hidrográficas, adaptada, con pocos resultados, de la experiencia estadounidense. Más tarde, la planeación recibió el impulso definitivo para su legitimación y adopción oficial con la formalización de la Alianza para el Progreso, en 1961 (Ander-Egg, 1981 y De Mattos, 1986, ambos citados en Massiris, 2006, p. 25). De esta manera, se estimularon la creación de organismos de planeación y la elaboración de planes de desarrollo en todos los países latinoamericanos.

Con estos planes se fomentaron expectativas desmedidas, otorgándoles funciones que llevaban implícitas las soluciones de problemas muy difíciles, como las condiciones económicas y sociopolíticas que incidieron en los alcances y limitaciones de los mismos, la tenencia de la tierra, la forma de inserción de estos países al comercio exterior, el atraso tecnológico y las grandes disparidades socioeconómicas internas, lo que terminó dando más importancia a la elaboración de dichos planes que a la práctica efectiva (Cibotti, 1975, citado en Massiris, 2006, p. 25). 
En el caso de México, se modificó la Constitución Política de los Estados Unidos Mexicanos en sus artículos 27, 73 y 115 para establecer las bases de la planeación nacional, y se creó la Ley General de Asentamientos Humanos (García Ortega, 2003, pp. 31-32). En consecuencia, se creó un marco normativo para la planeación en materia de desarrollo urbano y territorial que ha tenido modificaciones, como la integración de la ciudadanía en las decisiones de la planeación territorial, y que se estructura con base en las normativas estatales, conformando así un marco institucional en el cual la ciudadanía participa de diferentes formas.

De este modo, instituciones y ciudadanos requieren de canales para la interlocución, reglas claras e información completa que fomenten una relación de confianza entre las partes. Las instituciones, como los $\operatorname{marcos}^{1}$ que dan forma a esta interacción, son construcciones ideadas por el hombre que proporcionan una estructura para la acción (North, 1993, p. 14), y son el vínculo mediante el cual se establece la relación Estado-sociedad. Las instituciones representan limitaciones u oportunidades para la acción de las organizaciones, ya que establecen esquemas de coordinación y participación. Para Ayala-Espino (2003, pp. 12-13), estas reparten los costos, disminuyen la incompatibilidad de intereses y establecen las bases de la cooperación, conformando así un marco institucional que debe dar credibilidad y confianza a los agentes al establecer reglas claras para la participación y canales de información disponibles para la ciudadanía. En esta lógica, los marcos institucionales permiten o limitan la participación ciudadana e incluso fomentan la gobernanza. ${ }^{2}$

I. Se entiende el marco institucional como el "conjunto de reglas, normas, prácticas informales y tradiciones" (Vergara, 1997, p. 10).

2. De acuerdo a Mayntz (200I, Pp. I-8), la gobernanza moderna emerge en los países que ofrecen condiciones institucionales; es una forma de gobernar más cooperativa, alejada del modelo jerárquico. En el fondo, lo que reconoce la gobernanza es que existe una latente ingobernabilidad producto de un Gobierno 
A este marco de entendimiento Estado-sociedad se agrega el paradigma de la sustentabilidad ambiental, que involucra el medio ambiente, la economía y la equidad social. En materia ambiental, opera la desconcentración de tareas de gobierno para que las decisiones las tomen justamente los más involucrados y los Gobiernos locales (Pérez, 2009, p. 155). En materia económica, prima el poder de la iniciativa privada frente al Estado, en donde la primera ha hecho de la solidaridad un recurso escaso, y en el cual la sociedad civil aparece como un tercer sector que puede mediar entre las esferas del Estado y el mercado (Serrano, 1999, p. 80). En cuanto a equidad social, lo que rige es el acceso seguro y equitativo a recursos naturales básicos y a los servicios ambientales.

Ante este panorama, el papel del Estado es fomentar la innovación y la creatividad de los diversos ámbitos de la empresa y de la sociedad civil (Giddens, 2010, p. 191). La función de los ciudadanos en estos temas es diversa: comprende desde la revelación de los problemas, el intento por cambiar la vida de las personas (mejoras), la lucha por proyectos simbólicos y culturales (Melucci, 1999, p. 70), pasando por la organización de comités y la deliberación ciudadana en un marco de democracia deliberativa (Elster, 2001, p. 13), hasta involucrarse en tareas de gobierno. Se trata de participar en diferentes niveles de acuerdo con las oportunidades y limitaciones ofertadas por el marco institucional.

Para Arteaga (2003, pp. 69-78), la participación ciudadana puede darse en diferentes formas: información sobre decisiones; consulta y expresión de pareceres; decisión -interviniendo en la selección de una opción determinada-; control -cuando se vela por la ejecución de las decisiones 
tomadas-; y gestión. Para el autor, en el nivel de consulta la población no sólo conoce propuestas y decisiones, sino que expresa su parecer sobre un determinado evento y declara, en función de sus intereses, un conjunto de necesidades, aspiraciones y puntos de vista. En los últimos años, aunque con diferentes nombres, este esquema de participación se ha puesto en práctica en diversas áreas de la acción pública con el objetivo de incorporar a la ciudadanía en ciertos momentos de la construcción de una política o programa público.

Para el caso de México, la participación ciudadana en el nivel de consulta se ha establecido en la planeación del ordenamiento urbano, ecológico y territorial a partir de los años ochenta, proceso que se ha ido fortaleciendo paulatinamente y va de la mano con la conformación de un marco institucional para la planeación que pretende dar certezas a los agentes y promover la cooperación y las relaciones de confianza, elementos que abonan a una mejor y mayor participación ciudadana. ${ }^{3}$

\section{Procedimiento metodológico de los talleres de planeación participativa}

El presente estudio sobre la participación ciudadana en la planeación del ordenamiento urbano, ecológico y territorial en la frontera norte se hace a través del análisis de tres procesos de planeación en dos órdenes de Gobierno: a nivel municipal en Nogales, Sonora, y Juárez, Chihuahua; y a nivel estatal en Coahuila de Zaragoza. En dichos órdenes y lugares se aplicaron los siguientes instrumentos para la participación social: talleres de planeación participativa

3. La participación ciudadana en instrumentos de política ambiental ha sido una constante desde su implementación a partir de la Ley general del equilibrio ecológico y protección al ambiente (LGEEPA), en 1988; la fracción VII del artículo 20 bis 4 marca que en el ordenamiento ecológico local se establecerán los mecanismos que garanticen la participación de los particulares, los grupos y las organizaciones empresariales y demás interesados (Cámara de Diputados, 20 I4). 
(TPP), entrevistas semiestructuradas y encuestas tipo "Delphi”. Para el cumplimiento del objetivo planteado, en este trabajo se analiza lo correspondiente a los TPP.

Los TPP plantean la reflexión y la toma de decisiones con base en la participación de los actores más representativos de una comunidad; son una herramienta que forma parte de un esquema metodológico que tiene sus fundamentos en las propuestas hechas en los años sesenta por Paulo Freire y retomadas por Robert Chambers, con la idea de que las poblaciones locales son capaces de investigar, analizar y planear su desarrollo, por lo que los agentes externos toman el papel de facilitadores, permitiendo a las comunidades acceder a la toma de decisiones (Paré y Lazos, 2003, p. 27). Se reconoce entonces que los ciudadanos potencian el desarrollo, por lo que es necesaria su incorporación tanto en la definición del problema público como en su solución. Ante la ineficiencia del sistema de planeación tradicional, este esquema representa una innovación, ya que propone una lógica de acción de abajo hacia arriba (Terrones-Cordero, 2013, pp. 521-559).

Para la realización de los diferentes ejercicios elaborados y analizados en este trabajo, se llevaron a cabo dos talleres de planeación con perspectiva participativa para cada caso, y se incorporaron los saberes técnicos de los investigadores del ET con los de la ciudadanía participante. Con este fin, se convocó a actores de diferentes sectores para profundizar sobre los temas resultantes de los diagnósticos elaborados por el ET. En este punto, el ET definió la convocatoria de acuerdo con la representatividad de los actores, y también marcó el momento de participación de cada uno, ya fuera para opinar, calificar o decidir sobre los problemas analizados.

En Nogales, se identificaron los sectores que influyen en la ocupación del territorio y en el mantenimiento de los bienes y servicios ambientales o en la conservación de 
los ecosistemas y la biodiversidad: agropecuario, industria-comercio, turismo, conservación y urbano. En el caso de Juárez, los sectores reconocidos fueron el urbano, productivo, rural y desarrollo sustentable (conservación). En Coahuila, los sectores involucrados en la planeación son diversos y van desde el sector industria-comercio, turismo, urbano y agropecuario, hasta grupos ambientales y académicos. En el cuadro 1, se observa el número de asistentes a cada taller, así como la suma de la asistencia a los dos talleres realizados para cada caso de estudio.

Cuadro 1. Número de participantes en los TPP

\begin{tabular}{lccc} 
& Nogales & Juárez & Coahuila \\
Primer taller & 47 & 72 & 152 \\
Segundo taller & 42 & 31 & 169 \\
Total & 89 & 103 & 321 \\
\hline
\end{tabular}

Fuente: elaboración propia con base en Romo (2009, 2010 y 2012).

Una vez identificados los sectores, el ET procedió a convocar a actores representativos de cada sector, cuidando el equilibrio en el número de participantes. En las mesas de discusión, cada participante tuvo la misma oportunidad para externar sus ideas y preocupaciones sobre su territorio. Esto permitió centrar la atención sobre experiencias específicas y sus efectos, complementar y profundizar el tema, e incentivar en los actores participantes la apropiación del proceso.

El ET desarrolló una serie de técnicas participativas con el propósito de fomentar un diálogo informado entre los participantes; para ello, dotó a los actores de un diagnóstico pormenorizado de su territorio -ámbitos físicos, biológicos, económicos y sociales-, y estimuló la retroalimentación a partir de la reflexión y combinación de su experiencia vital con la de otros actores y con los datos proporcionados. Este ejercicio consolidó en ellos su perspectiva general 
del territorio y abonó a las siguientes fases del proceso de planeación del ordenamiento urbano, ecológico y territorial de cada caso.

\section{Geografía contextual}

En este apartado, se describen las principales características de los municipios de Nogales y Juárez, así como del estado de Coahuila. Geográficamente comparten su ubicación al norte del país y su colindancia con la frontera de Estados Unidos de América, aspecto clave para su desarrollo (véase mapa 1); en cuanto al medio natural, coinciden en su condición desértica y la relevancia de recursos naturales estratégicos como el agua.

El municipio de Nogales, Sonora, se caracteriza por la presencia de numerosas cadenas montañosas de baja altitud, pero escarpadas y separadas por valles aluviales profundos y estrechos. El clima predominante es semiárido desértico y su territorio forma parte de lo que se ha denominado "desierto sonorense". El principal centro urbano es la ciudad de Nogales, que también constituye uno de los centros urbanos más importantes del estado de Sonora. Como puerto fronterizo y centro de manufacturas, es un polo de atracción de personas e inversiones de diversos lugares; su crecimiento poblacional ha demandado, entre otras cosas, suelo y recursos naturales, y ha impactado al medio ambiente por la generación de residuos, emisiones y efluentes contaminantes; asimismo, directa o indirectamente, ha afectado la biota del municipio. 
Mapa 1. Localización de casos de estudio

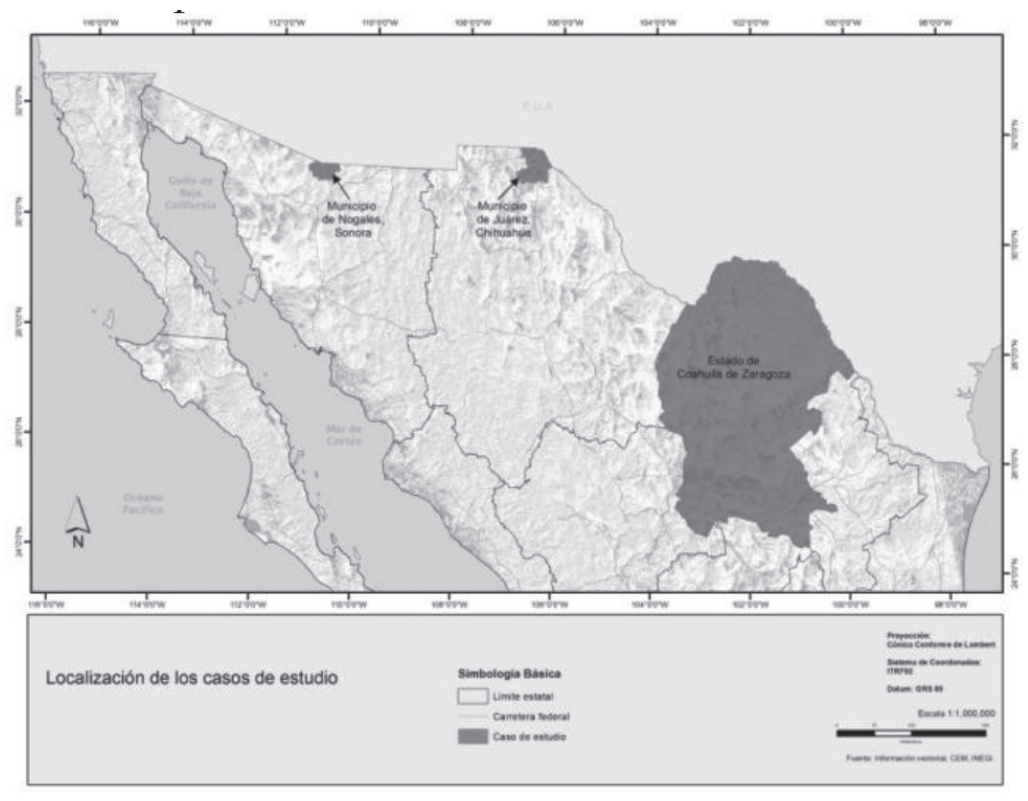

Fuente: información vectorial, CEM, INEGI.

El municipio de Juárez, Chihuahua, comparte las características climáticas de Nogales: cuenta con un clima seco desértico que, al localizarse dentro del denominado "desierto chihuahuense", lo hace muy extremoso. Cuenta con importantes recursos naturales en cuanto a flora y fauna, pero indudablemente el recurso natural más importante es el agua, no sólo por su ubicación, sino también porque la calidad y cantidad de dicho recurso se han visto seriamente afectadas.

Por su parte, Coahuila de Zaragoza es el tercer estado más grande del país, y la mayor parte de su territorio forma parte del desierto chihuahuense; cuenta con importantes recursos naturales estratégicos como el agua y su biota, amenazada por el crecimiento de cinco zonas metropolitanas que aglutinan más de $90 \%$ de su población; no obstante, 
mantiene importantes avances en materia ambiental al contar con diez áreas naturales protegidas (SEMA, 2012).

La dinámica demográfica de Nogales, Juárez y Coahuila ha presentado un importante crecimiento poblacional (véase cuadro 2), lo que ha repercutido en la demanda de recursos -principalmente de agua- y la liberación de residuos al ambiente.

Cuadro 2. Características demográficas del área de estudio (1960-2010)

\begin{tabular}{|c|c|c|c|c|c|c|c|c|}
\hline : & 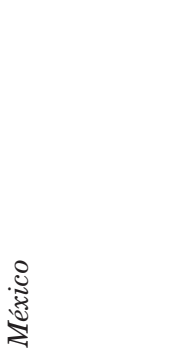 & 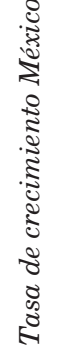 & 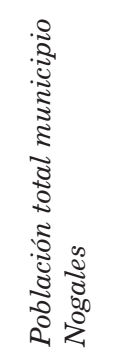 & 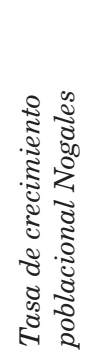 & 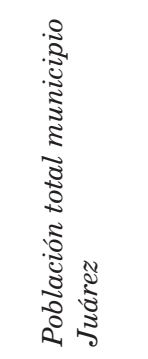 & 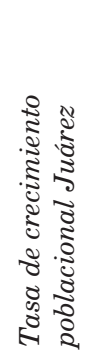 & 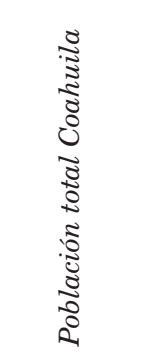 & 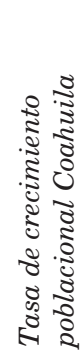 \\
\hline 1960 & $34,923,129$ & 3.07 & 37,657 & $\mathrm{~s} / \mathrm{i}$ & 276,995 & 7.72 & 907,734 & 2.15 \\
\hline 1970 & $48,225,238$ & 3.4 & 52,108 & 3.3 & 424,135 & 4.52 & $1,114,956$ & 2.87 \\
\hline 1980 & $66,846,833$ & 3.2 & 65,603 & 2.3 & 567,365 & 2.85 & $1,557,265$ & $\mathrm{~S} / \mathrm{l}$ \\
\hline 1990 & $81,249,645$ & 2.02 & 105,873 & 4.9 & 797,679 & 3.56 & $1,972,340$ & 1.55 \\
\hline 2000 & $97,361,711$ & 1.84 & 156,854 & 3.5 & $1,217,818$ & 4.34 & $2,298,070$ & 1.46 \\
\hline 2010 & $112,336,538$ & 1.38 & 220,261 & 3.2 & $1,332,131$ & 0.86 & $2,748,391$ & 1.8 \\
\hline
\end{tabular}

Fuente: elaboración propia con base en datos de INEGI (2014).

En el cuadro 2, se observa que el estado de Coahuila mantuvo tasas de crecimiento por debajo de la media nacional de 1960 a 2000, a diferencia de Nogales y Juárez, que presentaron un repunte importante en las décadas de los noventa y del año 2000. En el caso de Juárez, ocurrió un cambio importante: su tasa de crecimiento disminuyó de forma considerable entre 2000 y 2010, en principio por su dependencia estructural con el comportamiento de los indicadores macroeconómicos de los Estados Unidos, y 
también por las fuertes condiciones de inseguridad que se dieron en esta parte de la frontera, particularmente en el periodo 2008-2011.

En los tres casos de estudio, el crecimiento poblacional se ha presentado principalmente en los centros urbanos, lo que ha repercutido también en la alta concentración en estos de actividades económicas, de inversión, de servicios, de equipamiento y de documentos normativos sobre planeación. Esto ha provocado la fragmentación espacial en el territorio, ya sea municipal o estatal, ya que el resto de las localidades han permanecido prácticamente al margen de las inversiones.

En la economía de las tres zonas de estudio, predominan los sectores secundario y terciario, con alta propensión a la industria maquiladora de exportación hacia los Estados Unidos, por lo que los centros urbanos se desarrollan con base en este objetivo. Existe por ello una alta concentración de servicios que va de la mano con la lógica de desarrollo urbano seguida en las últimas décadas. Esto ofrece ventajas a sus habitantes, pero también desventajas, como la contaminación atmosférica relacionada directamente con el crecimiento urbano y las actividades económicas, así como la contaminación del agua.

La planeación del desarrollo urbano conlleva problemáticas particulares en torno a una dicotomía rural-urbana y una dinámica regional heterogénea, por lo cual se requiere la participación de un gran número de ciudadanos que den cuenta de las necesidades específicas para cada región; de esta manera, los mecanismos de participación ciudadana se vuelven un instrumento necesario en el contexto de la democracia liberal que ha obligado, hasta cierto punto, a que la sociedad civil se manifieste abiertamente en tareas que antes eran exclusivas de los Gobiernos, como es el caso de la planeación urbana y territorial. 
En el norte de México, esta tendencia cobra relevancia a raíz de las negociaciones del Tratado de Libre Comercio de Norteamérica (TLACAN), momento en que surgen diferentes movimientos sociales relacionados con el medio ambiente (Alfie y Méndez, 2000, pp. 40-54; Sabet, 2008, p. 93; Córdova, 2009, pp. 37-64). Desde entonces se han realizado un sinfín de gestiones en los centros urbanos y en el territorio fronterizo limítrofe con Estados Unidos, donde nuevos actores han estado pujando por llegar a consensos, de tal suerte que ha quedado de manifiesto que sólo con la participación de todos se puede avanzar para acabar con los desequilibrios urbanos y la amenaza que representa la expansión urbana para los ecosistemas.

\section{Incidencia de la participación}

La participación ciudadana en la planeación del desarrollo urbano, ecológico y territorial ha sido impulsada a través de los TPP. Estos esquemas son reconocidos como necesarios desde las normativas en materia de desarrollo urbano y territorial, como se ha podido observar en diferentes documentos de actualidad, entre ellos la Guía metodológica para elaborar programas de desarrollo urbano (SEDESOL, 2010). Nuevos actores se han sumado a la planeación urbana y territorial, entre los que se encuentran comités y asociaciones de vecinos (Córdova, 2005, pp. 79-118; 2013, pp. 145166), consejos consultivos de desarrollo urbano (Martínez y Córdova, 2015), comités de ordenamiento ecológico local (Romo, 2009 y 2010) y grupos de trabajo binacionales del Programa Ambiental México-Estados Unidos: Frontera 2020 (SEMARNAT-EPA, 2012). También cabe mencionar las diversas consultas públicas que generan los Gobiernos de los tres órdenes para tratar de legitimar planes y programas de diversa índole. 
En los planes analizados, particularmente en la identificación de problemas, se observan temas convergentes para los tres casos de estudio, como el mal manejo del agua, que es una situación crítica para Nogales y Juárez por la poca disponibilidad de agua subterránea. Otros problemas son el déficit de infraestructura, el uso inadecuado del suelo, la necesidad de conservación de ecosistemas, la falta de normatividad en temas relevantes como la vivienda, y las alternativas de desarrollo económico como el ecoturismo y el turismo cultural.

En general, los actores participantes en los TPP consideran que en cuanto al manejo del agua hay un desequilibrio en el uso del recurso, pues se destina cada vez más agua a las ciudades, quedando desprotegido el sector agropecuario, sin que sus integrantes puedan negociar con las autoridades programas y proyectos de sustentabilidad ambiental para el campo.

Con relación a la infraestructura, algunos actores, como los del sector agropecuario, se manifiestan por el mantenimiento de caminos y carreteras, y los actores del sector urbano por el establecimiento de un programa de movilidad urbana que acelere los tiempos de traslado dentro de la ciudad; como se puede ver, existen diferentes visiones sobre un mismo problema.

Con respecto al uso de suelo, hay coincidencia en señalar que este no es acorde con su propia vocación, y que existe además especulación por parte de particulares dentro y fuera de las ciudades. Junto con ello, se han dado procesos de expansión urbana sin planeación, lo que pone en riesgo áreas ambientalmente relevantes.

Por otra parte, los participantes consideran que la expansión urbana ha afectado la conservación de los ecosistemas, y que en algunas áreas ambientalmente relevantes no existen decretos de protección ni planes de manejo, y que, donde hay, no se realiza una supervisión adecuada de su aplicación. 
Referente a la normatividad, han detectado que en el caso de vivienda todavía se carece de un marco legal sólido que acompañe a los nuevos desarrollos de la periferia de las ciudades. Esto ha propiciado problemas de abandono de casas, inseguridad, costos de transporte altos, mal uso del equipamiento, basura y descuido de áreas verdes.

De esta manera, observan que la apuesta a la industria maquiladora de exportación ha acotado otras alternativas de desarrollo económico, como aquellas vinculadas al ecoturismo y la cultura. Tal vez el ejemplo más significativo de aprovechamiento del territorio en este sentido sea Coahuila, con los proyectos de protección y conservación de ecosistemas (véase cuadro 3).

Como alternativas a las anteriores problemáticas, los actores señalan con frecuencia una serie de aspectos que deben ser considerados por los tomadores de decisiones, como la sustentabilidad del agua, la protección de ecosistemas, el ajuste al marco normativo, la promoción del turismo y la cultura, la coordinación intersectorial, la planeación integral, la contaminación, entre otros.

De manera específica, en Nogales la alternativa planteada ante el problema del agua es la sustentabilidad mediante una extracción del líquido acorde con la recarga. Ante esta misma problemática, en Juárez los participantes señalan la necesidad de una voluntad política de los actores gubernamentales y la puesta en marcha de acciones concretas de políticas de uso de suelo. Del mismo tenor son las propuestas en Coahuila, pero se consideran una mejor alternativa los arreglos institucionales a través de los consejos consultivos. 
Cuadro 3. Análisis de la participación a través de la identificación de problemas, alternativas y factores institucionales importantes para la aplicación de las propuestas

\begin{tabular}{|c|c|c|c|}
\hline $\begin{array}{r}\text { Caso de } \\
\text { Estudio }\end{array}$ & Nogales & Juárez & Coahuila \\
\hline $\begin{array}{l}\text { Problemas } \\
\text { urbanos- } \\
\text { ecológicos- } \\
\text { territoriales }\end{array}$ & $\begin{array}{ll}\text { - } & \text { Mal manejo del } \\
& \text { agua } \\
\text { - } & \text { Déficit de } \\
\text { infraestructura } \\
\text { - Inseguridad } \\
\text { - Uso inadecuado de } \\
\text { suelo } \\
\text { - Conservación de } \\
\text { ecosistemas } \\
\text { - Necesidad de } \\
\text { ecoturismo y } \\
\text { turismo cultural }\end{array}$ & $\begin{array}{l}\text { - Mal manejo del agua } \\
\text { - Contaminación del } \\
\text { agua } \\
\text { - Uso inadecuado de } \\
\text { suelo } \\
\text { - Explotación y } \\
\text { degradación de } \\
\text { recursos naturales } \\
\text { - Inseguridad pública } \\
\text { - Déficit de } \\
\text { equipamiento e } \\
\text { infraestructura } \\
\text { - Planeación rebasada }\end{array}$ & 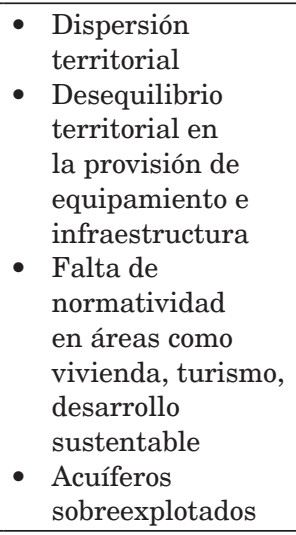 \\
\hline $\begin{array}{l}\text { Alternativas/ } \\
\text { propuestas } \\
\text { urbanas- } \\
\text { ecológicas- } \\
\text { territoriales }\end{array}$ & $\begin{array}{ll}\text { - Sustentabilidad } \\
\text { del agua } \\
\text { - Promoción de la } \\
\text { cultura y turismo } \\
\text { - Protección de } \\
\text { ecosistemas }\end{array}$ & 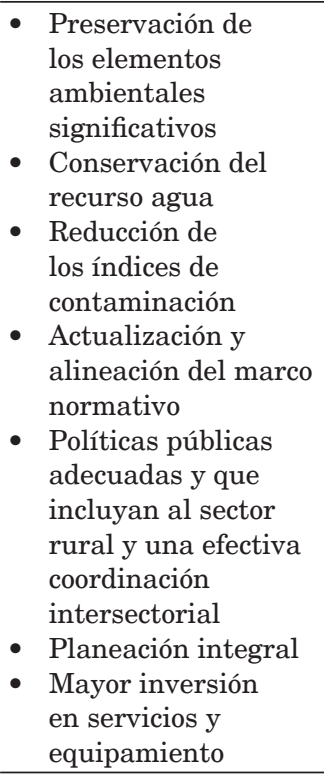 & $\begin{array}{l}\text { - Líneas de acción } \\
\text { y proyectos } \\
\text { estratégicos, } \\
\text { particularmente: } \\
\text { - Ordenamiento } \\
\text { Hidráulico } \\
\text { Metropolitano para } \\
\text { la Sustentabilidad } \\
\text { del Agua } \\
\text { - Actualización y } \\
\text { Alineación de la } \\
\text { Normatividad } \\
\text { sobre Desarrollo } \\
\text { Urbano y } \\
\text { Ordenamiento } \\
\text { Territorial }\end{array}$ \\
\hline
\end{tabular}


Verónica Martínez-Flores, Ma. de Lourdes Romo-Aguilar

y Gustavo Córdova-Bojórquez

\begin{tabular}{|c|c|c|c|}
\hline $\begin{array}{r}\text { Caso de } \\
\text { Estudio }\end{array}$ & Nogales & Juárez & Coahuila \\
\hline $\begin{array}{l}\text { Factores } \\
\text { institucio- } \\
\text { nales para la } \\
\text { aplicación de } \\
\text { propuestas } \\
\text { derivadas de } \\
\text { los talleres }\end{array}$ & $\begin{array}{l}\text { - Marco } \\
\text { institucional } \\
\text { avanzado } \\
\text { - Organismos } \\
\text { binacionales para } \\
\text { la gestión del agua } \\
\text { - Organismos } \\
\text { federales e } \\
\text { internacionales } \\
\text { para gestión de } \\
\text { infraestructura } \\
\text { - Participación } \\
\text { ciudadana } \\
\text { en planes de } \\
\text { desarrollo a nivel } \\
\text { de consulta } \\
\text { Aprovechamiento } \\
\text { de la gestión } \\
\text { transfronteriza } \\
\text { en el marco de } \\
\text { la cooperación } \\
\text { binacional } \\
\text { Decreto de } \\
\text { conservación de } \\
\text { ecosistemas }\end{array}$ & $\begin{array}{l}\text { - Marco institucional } \\
\text { avanzado } \\
\text { - Organismos } \\
\text { binacionales para la } \\
\text { gestión del agua } \\
\text { - Organismos federales } \\
\text { e internacionales } \\
\text { para gestión de } \\
\text { infraestructura } \\
\text { - Participación } \\
\text { ciudadana en planes } \\
\text { de desarrollo a nivel } \\
\text { de consulta } \\
\text { - Propuestas } \\
\text { ciudadanas de } \\
\text { desarrollo alternativo }\end{array}$ & $\begin{array}{l}\text { - Marco } \\
\text { institucional } \\
\text { avanzado } \\
\text { - Organismos } \\
\text { federales, estatales } \\
\text { y municipales para } \\
\text { la gestión del agua } \\
\text { - Organismos } \\
\text { federales e } \\
\text { internacionales } \\
\text { para gestión de } \\
\text { infraestructura } \\
\text { - Participación } \\
\text { ciudadana } \\
\text { en planes de } \\
\text { desarrollo a nivel } \\
\text { de consulta } \\
\text { - Decreto de } \\
\text { conservación de } \\
\text { ecosistemas } \\
\text { Propuestas de } \\
\text { región ecoturística }\end{array}$ \\
\hline
\end{tabular}

Fuente: elaboración propia a partir de los informes técnicos de los tres proyectos.

En cuanto a la protección de ecosistemas, las propuestas van encaminadas a la atención necesaria y el reconocimiento pleno de la riqueza natural de cada una de las zonas de estudio. La inclusión de la ciudadanía en las comunidades rurales debe ser inherente a cualquier acción pública que se establezca derivada de propuestas realizadas por expertos, relativas a zonas que deben ser protegidas del crecimiento urbano y del mal uso de suelo.

En cuanto al marco normativo, queda claro que se debe trabajar junto con el Gobierno para impulsar normas que cuenten con el consenso de la ciudadanía. En el caso de 
Coahuila, los ciudadanos participantes en los talleres señalaron la importancia de la construcción de un marco normativo en materia de desarrollo urbano que vincule las diferentes leyes relacionadas con este tema para tener una definición clara de las competencias y alcances de las mismas; también evidenciaron la necesidad de elaborar diagnósticos que permitan la protección ambiental y cultural, así como el desarrollo económico, considerando factores sociales y demográficos. La reflexión en torno a la necesidad de una normativa y regulación en materias como vivienda, desarrollo ecológico y turístico fue tan fructífera que permitió al ET la redacción de un documento que recoge las propuestas de proyectos, planes y programas de ordenamiento territorial, ecológico, hidráulico, de conectividad y de desarrollo integral de zonas metropolitanas; el resultado concreto fue la actualización de leyes y programas en materia de desarrollo urbano.

En la promoción del turismo y la cultura, las alternativas presentadas por los actores son variadas y están orientadas a aprovechar los territorios vastos en recursos naturales, paisajes y sitios históricos y arqueológicos que se habían olvidado, particularmente en Nogales y Juárez, por la apuesta al modelo maquilador. Dichas propuestas son suficientemente interesantes para ser consideradas por la iniciativa privada como nichos de inversión, siempre y cuando exista la certeza jurídica para hacerlo.

La coordinación intersectorial y la planeación integral son temas altamente criticados por los actores participantes; es manifiesta la desconfianza hacia las instituciones gubernamentales por sus malas actuaciones y por la poca importancia que le conceden a la planeación integral incluyente. Las propuestas son, de un lado, lograr una coordinación más alejada de los intereses partidistas y privados y, del otro, que se tome en cuenta a los pobladores que son afectados por las obras o actividades que se desarrollan en el territorio. Con 
lo expuesto hasta aquí, es fácil inferir que en lo tocante a los factores institucionales existe un marco legal avanzado, sin embargo, no hay una coordinación interinstitucional y de los organismos estatales que recoja las propuestas de los actores participantes que, cabe destacar, son válidas y plenas de contenido social.

Las propuestas de los participantes tienden a buscar el bienestar de la comunidad por medio de la solución de problemas con una visión sustentable para evitar afectaciones al medio ambiente, y ponderan el valor de las instituciones de cualquier nivel, e incluso de las instituciones binacionales que han prosperado en las últimas décadas. En consecuencia, la asignatura pendiente de las autoridades de los diferentes órdenes de Gobierno es responder a estas peticiones y alinear el marco normativo y legal, así como los factores institucionales, tomando en consideración a los organismos nacionales e internacionales para la cristalización de las propuestas (véase figura 1).

Figura 1. Problemas, propuestas y factores institucionales en la planeación integral

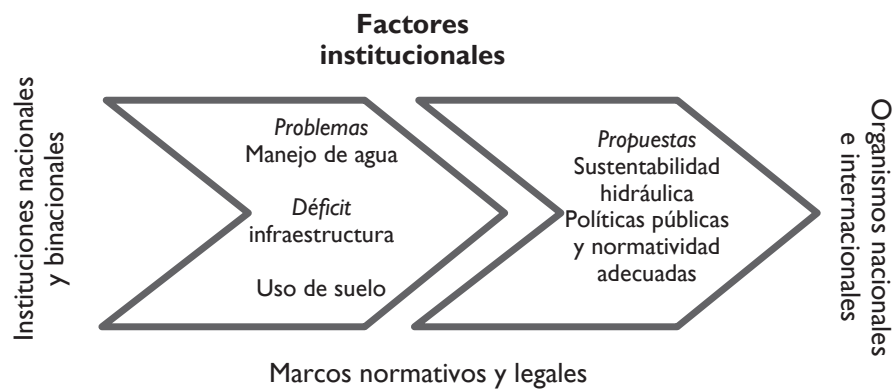

Fuente: elaboración propia.

Por ejemplo, para el manejo del agua en Nogales y Juárez, debe considerarse el factor binacional, ya que este recurso 
se comparte hasta cierto nivel e involucra a instituciones de ambos lados de la frontera. En este tema, intervienen instituciones como la Comisión Nacional del Agua (CNA); la Comisión Internacional de Límites y Aguas (CILA); los organismos locales de agua potable, alcantarillado y saneamiento; la Comisión de Cooperación Ecológica Fronteriza (COCEF); y los grupos de trabajo respecto al agua del Programa Ambiental México-Estados Unidos: Frontera 2020.

En el caso de Coahuila, la CNA está consciente de la sobreexplotación de los mantos acuíferos y de la necesidad de poner orden a los permisos de agua; de igual manera, los organismos operadores a nivel local reconocen los problemas de infraestructura, del servicio que se presta a la comunidad y de la escasez del recurso. No obstante, los actores sienten temor, ya que no hay una estrategia concreta para asegurar el recurso para las cinco zonas metropolitanas, las actividades agropecuarias y la conservación de los ecosistemas.

Para los tres casos, el Programa Ambiental México-Estados Unidos: Frontera 2020 significa un avance importante en materia de participación de nuevos actores sociales, como el gremio académico y la sociedad civil. Es significativo que este programa cuente con una agenda regional que respeta los ordenamientos legales de cada país y las disposiciones legales locales en la materia. Se aprovechan a este respecto los espacios de diálogo entre actores de ambos lados de la línea divisoria para introducir en la agenda de este programa aspectos de política pública de aplicación nacional, pero con impacto transfronterizo.

Por lo que compete a la infraestructura, en los tres casos analizados los actores reconocen un déficit de los Gobiernos locales frente a las crecientes inversiones que se necesitan para cubrir no sólo las necesidades de renovación de infraestructura hidráulica y vial, sino los requerimientos de las nuevas áreas de crecimiento en la periferia. En este sentido, los Gobiernos de los estados, junto con los munici- 
pios, han tratado de paliar el asunto gestionando recursos federales e internacionales, aprovechando la disponibilidad de recursos del Banco de Desarrollo de América del Norte (BDAN), mediante la certificación de proyectos por parte de la COCEF y el aval de los comités ciudadanos con procesos de participación pública aceptables, lo que ha permitido avanzar sustancialmente en la cobertura de infraestructura para estas zonas.

En torno al uso de suelo, la percepción es que los factores institucionales quedan a expensas de las relaciones de poder y de los intereses económicos, que empañan la oportuna intervención estatal y social. Desde inicios de la década pasada, la especulación con el uso de suelo por los nuevos desarrollos de vivienda tomó por sorpresa a las instituciones locales, carentes de controles urbanos, ambientales y sociales adecuados para regular la expansión urbana. A raíz de esto, la planeación del desarrollo urbano, ambiental y territorial cobró relevancia, y las distintas dependencias se abocaron a formular o reformular nuevos programas con base en la participación ciudadana.

En Nogales, en 2008, se actualizó el Programa de Desarrollo Urbano del centro de población, y dio inicio la elaboración del Programa de Ordenamiento Ecológico del Territorio; en Juárez, se actualizó el Programa de Desarrollo Urbano del centro de población, en 2010, y se elaboró y aprobó el Programa de Ordenamiento Ecológico del Municipio de Juárez; en Coahuila, se avanzó en la elaboración y actualización de programas de desarrollo urbano de los centros de población, y en la formulación de los planes metropolitanos y, en 2012, se aprobó el Programa de Desarrollo Urbano y Ordenamiento Territorial del estado (Romo, 2012).

Sobre la conservación de ecosistemas, los actores son sensibles a la relevancia del contexto fronterizo, lo que ha ayudado a visibilizar la necesidad de la conservación de territorios con gran riqueza biótica. No obstante, en Nogales

\section{0}


poco se ha avanzado en la elaboración e implementación de proyectos institucionales para conservar los ecosistemas ribereños, las fuentes de agua de la ciudad y los corredores biológicos que atraviesan la frontera. En Juárez, en la última década, se ha avanzado con el decreto de protección de flora y fauna de Samalayuca (Diario Oficial de la Federación, 2009), gracias a la intervención de los miembros de varios ejidos, instituciones académicas y del Gobierno federal en el seno del Comité de Ordenamiento Ecológico Local (Romo, 2010). En este rubro, el avance de Coahuila es importante y cuenta con reconocimiento social; sin embargo, a excepción de la zona de La Laguna, que a nivel municipal cuenta con un área natural protegida (Jimulco), los demás centros urbanos no tienen este tipo de figuras.

En cuanto a la normatividad, los actores se sorprenden de que sus Gobiernos locales apenas estén adaptando una serie de lineamientos acordes con los cambios en la legislación federal y las directrices globales, como los relacionados con el cambio climático; enfatizan la falta de regulación del crecimiento urbano y el cuidado de los recursos naturales, particularmente del agua; y advierten que la normatividad debe ser aplicada a todos por igual, y que la "politización" de este tema merma la eficiencia, la eficacia y la rendición de cuentas del ejercicio público.

De igual manera, han constatado que en Nogales y Juárez las alternativas de desarrollo económico se circunscriben a la industria maquiladora de exportación. De hecho, la estructura burocrática de ambos lugares se ha perfilado en gran medida para el cumplimiento de este propósito. Hay, empero, voces autorizadas, como la de los ejidatarios de Samalayuca, en el municipio de Juárez, que apuestan por un desarrollo alternativo basado en el turismo rural (ecoturismo), exhibiendo no sólo los médanos (dunas de gran tamaño y extensión), sino el arte rupestre en más de cincuenta sitios encontrados y la riqueza hídrica que brota 
del suelo en lo que llaman "ojos de agua". En cambio, en Coahuila, Cuatro Ciénegas se ha consolidado como región ecoturística gracias al apoyo de diversas dependencias públicas y privadas.

En suma, los actores sociales participantes en los TPP han sido enfáticos al señalar conflictos relacionados con el medio ambiente y la importancia de la planeación participativa para el ordenamiento ecológico y territorial, de lo que se desprende que los TPP son fundamentales y valiosos para la construcción de consensos y para determinar problemáticas y propuestas; más aún, son herramientas ideales para evaluar las políticas públicas, aunque en este punto queda camino por recorrer.

\section{Conclusiones}

Los tres casos de estudio realizados en la frontera norte de México -Nogales, Juárez y Coahuila-demostraron que los TPP son un método eficaz para la incorporación de la participación ciudadana en la planeación del ordenamiento urbano, ecológico y territorial. El análisis establece que esta herramienta es útil para conciliar intereses, priorizar problemas y decantar alternativas, así como para poner en perspectiva factores institucionales que deben ser atendidos.

Se constató que los actores sociales responden positivamente cuando se les convoca para discutir asuntos relacionados con el territorio, tanto en materia urbana como ambiental, en los niveles municipal o estatal. Un logro importante en las mesas de trabajo fue la consecución del diálogo entre los sectores convocados: académico, productivo, gubernamental, organizaciones de la sociedad civil, así como cámaras, colegios y barras que representan al ámbito privado. Por ejemplo, dinámicas como el crecimiento desordenado derivado de la ambición de grupos e individuos no pueden ser contenidas por la sola actuación del Gobierno

\section{2}


y, en este sentido, la deliberación que ofrecen este tipo de ejercicios mediante talleres o figuras democráticas, como consejos consultivos y comités temáticos, resulta fructífera para tratar asuntos complejos relacionados con lo urbano, ecológico y territorial.

Las propuestas resultantes de las prácticas realizadas en Juárez, Nogales y Coahuila convergen en cuanto a la importancia que reviste la administración del territorio y las instituciones encargadas de la misma. Los actores señalan que debe aplicarse la normatividad y revisarse la congruencia entre los distintos lineamientos jurídicos relacionados con la planeación y el ordenamiento ecológico y territorial, y dan relevancia a la necesidad de la coordinación interinstitucional eficaz y eficiente. También es coincidente la demanda de un proceso de planeación integral que incluya la participación ciudadana. En este punto, figuras como los consejos ciudadanos y los consejos consultivos constituyen un auxiliar en el proceso cotidiano de toma de decisiones; sin embargo, los TPP son imprescindibles en la elaboración de proyectos y programas estratégicos en los niveles municipal y estatal.

Se documentó que los diferentes actores reconocen tácitamente a las instituciones estatales como rectoras del desarrollo urbano, el cuidado del medio ambiente y la distribución adecuada del territorio, aunque paradójicamente manifiestan desconfianza hacia sus representantes. Ante ello, se reafirma el interés ciudadano por hacer mejor uso del territorio en beneficio de la colectividad, y se evidencia la incompatibilidad de esta visión con las acciones de los funcionarios públicos, creando así un marco institucional frágil, no adecuado para el ejercicio de la gobernanza.

Este tipo de técnicas permite observar problemáticas concretas, alternativas de solución y factores institucionales, abonando de manera constructiva a los procesos de planeación. En el discurso general de los actores participantes, los temas convergentes son el manejo adecuado 
del recurso agua, la protección de ecosistemas, el ajuste de marcos normativos, la coordinación intersectorial y la planeación integral.

Para el tema del agua, es central el manejo estratégico y de largo plazo para afianzar los proyectos urbanos, de conservación y de proyección del desarrollo económico. En este sentido, proyectos de agua transfronterizos aseguran la no politización del tema y es posible que la planeación de largo plazo con el consenso de actores de ambos lados pueda ser la solución definitiva.

En la protección de ecosistemas, los actores reconocen que se han sentado las bases para desarrollar políticas de conservación y aprovechamiento sustentable, e incluso para la restauración; no obstante, todavía se sienten lejanos de participar e incidir en la definición del uso de suelo en los centros urbanos, dada la alta especulación y las pocas reservas territoriales que tienen los municipios. A pesar de ello, se advierte el compromiso ciudadano de seguir participando en la planeación del territorio. El ajuste de la normatividad es un clamor de muchos actores, ya que estiman que hay descontrol por la falta de instrumentos de regulación precisos o por desatención de las autoridades responsables de aplicar estos en beneficio de las mayorías.

La falta de un destino definido del suelo en vastas zonas aledañas a los centros urbanos hace que quienes anhelan urbanizar lo más posible se aprovechen de ello para darle valor de cambio e insertarlo en el mercado tan pronto como se pueda. Algunas de las ideas planteadas por los actores son el fomento del ecoturismo, la exposición de sitios culturalmente relevantes y la promoción del patrimonio intangible; se percibe, sin embargo, el titubeo por parte de los proponentes ante la vacilación de las mismas autoridades.

Los aspectos más relevantes de esta experiencia son la valoración del territorio por parte de los actores participantes en los TPP; el encuentro con herramientas de gestión 
sencillas que permiten congregar diversas posturas y formas de acción; el logro de consensos sobre temas relevantes y la construcción de rutas de acción en un esquema de planeación; y, sobre todo, la esperanza que genera en los participantes la posibilidad de nuevas formas de entendimiento que redunden en un mejor manejo de los espacios urbanos y territoriales, en armonía con el medio ambiente.

Los TPP forman parte de un proceso deliberativo donde participan diferentes grupos. Entre los alcances de este ejercicio, cabe destacar la cantidad de la respuesta y la calidad de la participación ciudadana, pero también han de mencionarse limitantes como el proceso de identificación de actores, la capacidad de convocatoria, la representación sectorial y las dinámicas grupales que deben manejarse. El ET sorteó con éxito estas consideraciones, logrando decantar con claridad convergencias en problemas y alternativas de solución para obtener así buenos resultados.

Se concluye que es primordial la gestión interinstitucional transversal, pues se observó que las alternativas de solución implican acciones que requieren de la intervención de diferentes instituciones y de más de un orden de Gobierno y, en este sentido, los vínculos interinstitucionales e intergubernamentales se vuelven una necesidad que influirá sobre la factibilidad de los proyectos. De igual forma, se reconoce la importancia de la participación de organismos binacionales e internacionales interesados en temas como agua, infraestructura y recursos naturales, que posibilitan la gestión de proyectos para dar respuesta a tales problemáticas. La suma de estos factores conforma el marco institucional que si bien aún no es perfecto, sí presenta espacios para la participación de la ciudadanía y posibilita su incidencia.

Finalmente, se puede concluir que los TPP son una herramienta útil para la deliberación y la incidencia de la ciudadanía en los planes y programas de desarrollo ecológico, territorial y urbano, y que pueden coadyuvar al ejercicio 
de una real gobernanza, siempre y cuando exista un marco institucional fuerte que permita mayores espacios de participación efectiva de la sociedad.

Fecha de recepción: 31 de octubre de 2014

Fecha de aceptación: 16 de junio de 2015

Bibliografía

Aguilar, L. (2010). "El futuro de la gestión pública y la gobernanza después de la crisis”. Frontera Norte, 22(43), I87-2। 3 .

Alfie, M. y Méndez, L. (2000). "Deterioro ambiental y movimientos sociales en Ciudad Juárez y Matamoros. Similitudes y diferencias". El Cotidiano, I6(I0I), 40-54.

Arteaga, C. (2003). "La participación ciudadana: un breve acercamiento", en Chávez, J. (coord.), Participación social: retos y perspectivas (pp. 69-78). México: UNAM, Plaza y Valdés.

Ayala Espino, J. (2003). Instituciones para mejorar el desarrollo. Un nuevo pacto social para el crecimiento y el bienestar. México: FCE.

Cámara de Diputados (2014). Ley general del equilibrio ecológico y protección al ambiente. México: Cámara de Diputados. Recuperado de: http://www.diputados.gob. $\mathrm{mx/LeyesBiblio/pdf/I} \mathrm{48.pdf}$

Córdova, G. (2005). "Participación ciudadana y gestión del agua: líderes de comités de vecinos en Ciudad Juárez, Chihuahua". Estudios Fronterizos, 6(I2), pp. 79-II8. (2009). "La gestión del agua en Ciudad Juárez, Chihuahua. Líderes y miembros de ONG”, en Dirección Regional Noroeste (breviarium). Gestión y participación ciudadana en el estado de Chihuahua (pp. 37-66). México: El Colegio de la Frontera Norte. (20I3). "Liderazgo vecinal y desarrollo urbano en Nogales, Sonora”, en Córdova, G.; Dutram, J.; Lara, B. 
y Rodríguez, J. (coords.), Desarrollo humano transfronteBibliografía rizo, retos y oportunidades en la región Sonora-Arizona (pp. 145-166). México: El Colegio de Sonora, El Colegio de la Frontera Norte, Universidad de Sonora, Universidad Estatal de Sonora.

De Mattos, C. (1986). "Paradigmas, modelos y estrategias en la práctica latinoamericana de planificación regional”. Pensamiento Iberoamericano. Revista de Economía Política, (I0), I4-35.

Diario Oficial de la Federación (2009). “Decreto por el que se declara área natural protegida, con el carácter de área de protección de flora y fauna, la zona conocida como Médanos de Samalayuca, localizada en los municipios de Juárez y Guadalupe, en el estado de Chihuahua". Recuperado de: http://dof.gob.mx/nota_detalle.php?co digo $=5093564 \&$ fecha $=05 / 06 / 2009$

Elster, J. (200I). La democracia deliberativa. Barcelona: Gedisa, FCE.

García Ortega, R. (2003). Monterrey y Saltillo, hacia un nuevo modelo de planeación y gestión urbana metropolitana. Tijuana, B.C.: El Colegio de la Frontera Norte.

Giddens, A. (1999). La tercera vía. Madrid: Taurus.

(20I0). La política del cambio climático. Madrid: Alianza Editorial.

Graizbord, B. (1999). "Planeación urbana, participación ciudadana y cambio social”. Economía, Sociedad y Territorio, 2(5), |49-|6|.

INEGI (20I4). Banco de Información INEGI. México: INEGI. Recuperado de: http://www.inegi.org.mx/sistemas/ biinegi/default.aspx

Martínez, V. y Córdova, G. (20I5). "Los consejos ciudadanos, mecanismos de deliberación para el desarrollo urbano y territorial. Caso Coahuila”, en Ochman, M. y Rodríguez-Oreggia, E. (coords.), Incidencias de políticas públicas en México (pp. 355-375). México: EGAP-ITESM. 
Bibliografía

Massiris, A. (2006). "Políticas latinoamericanas de ordenamiento territorial: realidad y desafios”. Tunja: Dirección de Investigaciones de la Universidad Pedagógica y Tecnológica de Colombia. Recuperado de: http://www.massiris. com/20 I /09/libro-politicas-latinoamericanas-de.html

Mayntz, R. (200I). “El Estado y la sociedad civil en la gobernanza moderna”. Revista del CLAD Reforma y Democracia, $21,1-8$.

Melucci, A. (1999). Acción colectiva, vida cotidiana y democracia. México: El Colegio de México.

North, D. (1993). Instituciones, cambio institucional y desempeño económico. México: FCE.

Paré, L. y Lazos Chavero, E. (2003). Escuela rural y organización comunitaria: instituciones locales para el desarrollo y el manejo ambiental. México: Instituto de Investigaciones Sociales, UNAM, Plaza y Valdés.

Pérez, E. (2009). "Desarrollo y medio ambiente, algunas miradas desde las ciencias sociales". Revista Mexicana de Ciencias Políticas y Sociales, 5 I (205), I 4 I - I 6 I.

Ramírez, A., et al. (2005). El ordenamiento ecológico territorial participativo, instrumento para el desarrollo rural sustentable: el caso del municipio de Álamos, Sonora. México: Instituto Nacional de Ecología y Cambio Climático. Recuperado de: http://www2.inecc.gob.mx/publicaciones/libros/670/cap3.pdf

Romo Aguilar, M. (responsable) (2009). Programa de Ordenamiento Ecológico Territorial del Municipio de Nogales, Sonora (informe técnico). México: CEDES, SEMARNAT, El Colegio de la Frontera Norte.

- (responsable) (2010). Programa de Ordenamiento Ecológico y Territorial del Municipio de Juárez. Derivado del proyecto Zonificación y Ordenamiento ecológico y Territorial del Municipio de Juárez (informe técnico). México: Fondo Mixto CONACYT-Gobierno Municipal de Juárez, El Colef.

\section{8}


(responsable) (2012). Programa de Desarrollo Urbano

Bibliografía y Ordenamiento Territorial del Estado de Coahuila de Zaragoza (informe técnico). México: SEDESOL, El Colef. Sabet, D. (2008). Nonprofit and their networks, cleaning the water along Mexico's northern border. EE. UU.: The University of Arizona Press.

Salamanca, L.; Argueta, L. y Altschul, F. (200I). La planificación territorial participativa en el ámbito local. El Salvador: Sistema de Asesoría y Capacitación para el Desarrollo Local, Fundación Ford.

Sánchez, L. (2007). "Fragmentación social y planeación territorial”. Revista Bitácora Urbano-Territorial, I (I I), 28-39.

SEDESOL (2010). Guía metodológica para elaborar programas de desarrollo urbano. México: Secretaría de Desarrollo Social, Dirección General de Desarrollo Urbano y Suelo. SEMA (20 I I). Programa Estatal de Medio Ambiente 201 I-20 I 7 , Secretaría de Medio Ambiente de Coahuila de Zaragoza. México: SEMA. Recuperado de: http://coahuila.gob.mx/ archivos/pdf/Publicaciones/MEDIO\%20AMBIENTE.pdf Semarnat-ePA (20I2). Programa Ambiental México-Estados Unidos: Frontera 2020. México: SEMARNAT-EPA. Recuperado de: http://www2.epa.gov/sites/production/files/ documents/frontera2020.pdf

Serrano, E. (1999). "Modernidad y sociedad civil", en Olvera, A. J. (coord.), La sociedad civil de la teoría a la realidad (Pp. 55-82). México: El Colegio de México.

Terrones-Cordero, A. (20I3). "Planeación participativa para elaborar un plan de desarrollo municipal: el caso de Acaxochitlán, Hidalgo". Economía, Sociedad y Territorio, 13(2), 521-559.

United Nation (1987). Our Common Future. EE. UU.: United Nation. Recuperado de: http://conspect.nl/pdf/Our_ Common_Future-Brundtland_Report_1987.pdf

Vergara, R. (1997). "El redescubrimiento de las instituciones: de la teoría organizacional a la ciencia política”, en 
Verónica Martínez-Flores, Ma. de Lourdes Romo-Aguilar y Gustavo Córdova-Bojórquez

Bibliografía March, J. y Olsen, J., El redescubrimiento de las instituciones. La base organizativa de la política (pp. 9-40). México: FCE, CNCPAP, UAS. 